\title{
This Nudge Was Not Enough: a Randomised Trial of Text Message Reminders of Court Dates to Victims and Witnesses
}

\author{
Jonathan R. Cumberbatch ${ }^{1}$ - Geoffrey C. Barnes ${ }^{2}$
}

Published online: 18 June 2018

(C) The Author(s) 2018

\begin{abstract}
Research Question Do text messages to mobile phones of victims and witnesses two or three days before they are scheduled to appear in court reduce their non-appearance rates in minor criminal cases?

Data A sample of 811 victims and witnesses sent a postal notice to attend a specific magistrates' court in Staffordshire on a specific date. Cambridge Crime Harm Index value of the criminal charges, court appearance and trial outcome data were collected in all cases.

Methods A text message reminder was randomly assigned to be sent to 405 treatment cases 2-3 days before the court trial date. Treatment as delivered comprised $84 \%$ of the treatment group.

Findings The base rate of victims and witnesses not attending magistrates' trials prior to the RCT was $26 \%$. The non-attendance rate during the RCT was $22 \%$ in the control group and $24 \%$ in the treatment group $(p=0.444)$. A $14 \%$ higher guilty rate for trials attended by the treatment group (58\%) than the control group $(51 \%)$ was marginally significant $(p=0.052)$. No treatment-control differences in attendance were found when moderated by crime type or Crime Harm Index score.

Conclusion A text message in isolation did not significantly affect victim and witness attendance at criminal cases in the three magistrates' courts. However, it does show that texting is a reliable, quick and cheap method of communicating with witnesses.
\end{abstract}

Jonathan R. Cumberbatch

Jonathan.Cumberbatch@staffordshire.pnn.police.uk

1 Staffordshire Police, Stafford ST18 0YY, UK

2 University of Cambridge, Cambridge, UK 
Keywords "Nudge" · Crime Harm Index · Court appearance · Victims witnesses · Randomised controlled trials

\section{Introduction}

Witness attendance at court is a long-standing problem, the responsibility for which in England is primarily police led. Police define the care of witnesses (including victims) as the delivery of communications needed to insure court appearance. Yet as communication systems change dramatically in the twenty-first century, many English police forces still used nineteenth-century methods of notifying witnesses when to appear in court: letters, envelopes and stamps.

The House of Commons Committee of Public Accounts (2017) estimated the central government spending on the courts system at approximately $£ 2$ billion a year, and in the year to September 2015, around 1.7 million offences were dealt with through the courts. The National Audit Office (2016) reported that magistrates' courts in England and Wales had seen an increase in cases of $4 \%$, while the length of time spent preparing for magistrates' court cases increased from 119 to 133 days $(10 \%)$ between the year ending September 2011 and the year ending September 2015. In 2015, 10,922 magistrates' court trials collapsed because witnesses did not come to court. It is difficult to define this as in a percentage, due to the Ministry of Justice (2015) statistical bulletins only counting cases - many of which will not get to trial. Yet, the absolute number is a large target for improvement.

The National Audit Office suggests that many witnesses have had no prior contact with the system. In many cases, considerable time and effort is spent, providing information and reassurance to try to have them attend court, yet that effort may backfire. The House of Commons Committee of Public Accounts (2017) suggested that only $55 \%$ of people who had given evidence in court as a victim or witness would be prepared to do so again.

Coercing attendance is costly and of questionable effectiveness. The legislative tool to force witness attendance can be found in the form of a witness summons, which falls under Section 97 of the Magistrates' Court Act (1980). The production and serving of a summons involve considerable work from both the police and Crown Prosecution Service.

One concern can be seen in the national joint review conducted by Her Majesty's Inspectorate of Constabulary (HMIC) and Her Majesty's Crown Prosecution Service Inspectorate (HMCPSI) (2013) of England and Wales. The review of the quality of 137 witness lists found that police officers who should be submitting documents identifying dates where witnesses are available for court were correct in just $15 \%$ of the cases. Furthermore, in over a quarter of case files, the review was unable to find any witness availability information in the file.

The vast majority of English cases in which witnesses are required to appear are heard in the lower courts, with lower harm cases. The research Davis (1983) undertook in Brooklyn, USA, demonstrated that securing witness attendance is more difficult for less serious cases than for those in which the potential for punishment was greater. This is supported by Erez and BienKowska (1993) who postulate that victim participation in proceedings is associated with victim satisfaction over the sentence and with the 
criminal justice service in general. This view has recently been supported by a report by the UK media (BBC 2016) reporting HMCPSI figures that $2.1 \%$ of trials in the crown court and $6.8 \%$ of trials in the magistrates' court were cracked (meaning the trial was cancelled on the day; witness non-appearance contributes to these figures ${ }^{1}$ ) in 2014 2015, compared with 1.8 and $6.3 \%$, respectively, the previous year. These figures clearly suggest that the challenges of maintaining witness testimony are a key feature of the rule of law.

\section{Theoretical Context of Nudge Messages}

SMS messaging appears to have not been widely used to investigate witness attendance; however, there are other areas where it has been used. Examples of this are seen with medical appointments, citizens being encouraged to vote, collection of delinquent fines and taxes. Haynes et al.'s (2013) nudge research conducted a range of texts in different contexts, which strongly suggested that text messaging has the potential to influence behaviour. However, for witnesses and victims, this finding may not be generalisable.

In this arena, the nudge is aimed at all witnesses that the Crown Prosecution Service (CPS) requires at court: those who have agreed to attend and those who are unsure or unwilling and potentially have the threat of a court summons. For the purposes of this research, no participants are attending court as accused criminals. However, failure to attend court under summons may result in criminal punishment. As a result, the research has a dilemma over whether the nudge message is seen as an impersonal or personalised notice, with a threat to punish.

Halpern (2015) describes a nudge message as essentially a means of encouraging or guiding behaviour in an unobtrusive manner. This is supported by Kahneman (2012) who suggests that a nudge can help people make good decisions without curtailing their freedom. The nudge message in this case is not just to remind a witness of their commitment; it is an attempt to change the mind of a witness who may not wish to attend court. When a nudge message is simple and personalised, Halpern (2015) postulates that sometimes behaviour changes with a surprisingly light touch.

In addition, Halpern (2015) also intimates that if you want to encourage someone to make or change a decision, make it easy to do so. The design of the present experiment attempts to test that hypothesis with a personalised and simple message sent with ease for the recipient to understand and act upon.

\section{Using a Name}

It can be suggested that customising a text is a significant ingredient towards fulfilling an aim via nudge messaging. Bargh's (1982) work supports this by declaring that there is a wealth of psychological evidence proving the special power of names in attracting attention. Personalising a text message with a name can activate the so-called 'cocktail party effect' which was replicated in Conway and Cowan's (2001) review, whereby people filter out competing stimuli and refocus their attention when their name is mentioned. Furthermore, there is also evidence to suggest this has been shown to

\footnotetext{
${ }^{1}$ Witness non-attendance is a contributor to cracked cases alongside other problems such as plea changes.
} 
operate even when names appear in printed text (Shapiro et al., 1997). Yet, there is no evidence we can find about whether the use of names in court summonses can change the behaviour of those summoned.

\section{Research Question}

Do text messages to mobile phones of victims and witnesses two or three days before they are scheduled to appear in court reduce their non-appearance rates in minor criminal cases, relative to those who do not receive the text messages?

\section{Data and Research Setting}

\section{Setting}

The research question was tested during an ongoing structure change within Staffordshire's Justice Services Department. The re-structuring disbanded the Witness Care Service in its historically centralised format, with work responsibilities disseminated into geographical work hubs. Throughout the RCT, numerous caseworkers who were assigned to send out witness nudge text messages were leaving Staffordshire Police. As a result, intrusive daily tracking of that work was required to realise an acceptable treatment integrity rate. The trials were based at three magistrates' courts, these being North Staffordshire, Cannock and Derby.

The data required to deliver this RCT were extracted from the Witness Management System (WMS). This system's ownership and administration sits with the CPS. All the information relating to witnesses required to give evidence at magistrates' court exists upon the WMS. This RCT makes the assumption that the data inputted onto the WMS is the most accurate source for witness information. The following elements related to each witness 'warned' (the legal terminology used) to give evidence at a trial was recorded:

- Name

- Date of birth

- Gender

- Address

- Mobile phone number

- Ethnicity

- Date notified for court

- Witness type
- Date the witness confirmed their attendance

- Magistrates' court

- Court attendance time

- Trial URN number

- Crime type for trial

- Witness attendance

- Court outcome

G*Power software was used to determine the sample size needed for the testing of the difference between treatment and control groups. The required sample size for this RCT was a minimum of 788. The RCT lasted for just over 15 weeks with an average of 54 participants each week. The statistical power calculation that identified the sample 
size is found in Cumberbatch (2017). The required size provided statistical power of 0.8 . This means that in $80 \%$ of the time, if there is a true difference between groups, the RCT should be able to detect that difference as statistically significant. This also means that in $20 \%$ of the time with a true difference, an RCT of that sample size will not obtain a statistically significant effect between the two groups, even though there really is an effect in reality.

The West Midlands CPS had confirmed that witness attendance is only recorded on the WMS, and as a result, there is no historical statistical data at hand that is specific to this research for magistrates' court. The CPS realise periodic data which is slightly difficult to interpret in relation to just a 'yes' and 'no' count as to whether the witness has turned up or not. The data suggest a non-attendance rate of approximately $20 \%$. As a result, to ensure a bench mark for the research, data was gathered from the WMS between the same calendar time periods within this RCT (from 24 April to 8 August 2016) to establish comparable data for witness attendance. Every court trial was manually reviewed on the WMS, and the data were inclusive of all witnesses called to give evidence throughout the stated time periods. The reason for using the same dates was to include the same peak annual leave period, which affected trial volume and type.

\section{RCT Planning}

When the data collection categories and the number of required participants were established, a planning and delivery timetable was drawn up with key dates, and these are listed in the following:

20/03/2017 1 week of trial nudges to establish the practicality of delivering the research; this was done with 40 witnesses who were allocated to caseworkers

24/03/2017 A 'pre-mortem' meeting (Kahneman 2012) with selected caseworkers and supervisors to establish both positive and negative elements of the nudging process as well as the identification of worse case scenarios

19/04/2017 Briefing/training to all caseworkers from Witness Care and North and South Justice Services hubs regarding the research delivery

20/04/2017 Initial witness information extraction from the WMS for the first week of nudge texting

21/04/2017 Circulation of the first witness list requiring nudges to all caseworkers alongside the standard requirement for delivery

24/04/2017 Official start of nudge text delivery for trials commencing on 27 April 2017

08/05/2017 Initial review meeting with selected caseworkers and supervisors to establish initial concerns and problems

Data collection runs as normal thereafter

04/08/2017 Review the participant numbers within the trial to ensure that 788 is achieved

08/08/2017 Data collection complete

One element of the pre-mortem, which Klein (2007) describes as a meeting process to identify all the possible problems before implementation commences, was to evaluate perceived risks which had been identified by caseworkers and supervisors. There had been a simple process established to randomise court trials as opposed to 
individual witnesses. However, from an internal validity point of view, this would hugely disadvantage the research, as it contradicted the agreed research abstract. The view of the supervisors who managed the caseworkers was that there was great potential confusion for the witness when two or more witnesses selected for treatment were due to give evidence at the same trial and were in close contact with one another or living at the same address. There was the concern from the Witness Care and the Vulnerable Victims Unit that if one witness is selected for the treatment and the other is selected for the control group, the control witnesses may perceive that they are not required for court after speaking with the witness who had received the nudge text reminder. All witnesses that fell into this scenario were tracked by a line manager to record potential problems for the initial review meeting.

The object of the research was to treat the person, not the trial at the conclusion of the planning stage. It was decided that randomisation will happen per victim and witness and not per trial. In addition, other considerations were made, these being the following:

- If a caseworker overlooked a single person, it would have less negative impact than overlooking a single trial which carried numerous participants.

- To randomise trials with differing numbers of victims and witnesses will have made it difficult to ensure evenly sized control and treatment groups.

Halpern (2015) suggests that with experiments of this nature, the subjects are best being blind, and the knowledge that they are in a special group may affect the way in which they behave. For this reason, no witnesses were made aware that they were part of the RCT. All included witnesses had their details recorded on an Excel spreadsheet. Random selection occurred weekly when all data had been extracted from the WMS and placed into a spreadsheet. The participants were selected for control and treatment, using a random number formula. This labelled the treatment group to receive the nudge text for court appearance and the control group that will not receive a nudge text. Due to the labour-intensive manner of data mining from the WMS, exporting Excel data into a specific randomiser for treatment or control allocation and then moving it back to Excel was not practical.

To ensure treatment integrity levels remained high throughout each week, reminder emails were sent to all caseworkers who were assigned by name to each witness. In total, 30 caseworkers were allocated nudge messages throughout the 15week period. The reminders were copied to each supervisor to oversee the work, and in addition, there was a requirement for the caseworker to place an electronic note on the WMS, advising that the nudge message had been sent. Each caseworker selected the trial(s) they were assigned on the email, and double checked that the information was correct from the WMS before a nudge text message was sent to the witnesses within 3 days of the trial.

The text message provided to each caseworker was standardised and was automatically copied to a witness notification email address (witness.notification@stafford shire.pnn.police.uk). Each 'sms' text message (example at appendix 2) sent from Microsoft Outlook generates a receipt that stated if the text message had been successfully delivered to the mobile number, or if it had failed. The caseworker then forwarded the delivery status message to the witness notification email address. The witness 
notification email address was used for the data collection and to audit the witnesses that have been nudged, as well as to record the delivery status of the message. The text message was standard general text with specific and personal information inserted, i.e. name, court, date, time and the URN number, as shown in the following:

STAFFORDSHIRE POLICE REMINDER: <Insert name $>$, you are required to give evidence at $<$ insert court name $>$ on $<$ insert date $>$. Upon arrival, please report to the main reception by $<$ insert time $>$. If you have a problem attending please contact us on 01785235648 (police reference < insert number> URN).

\section{Testing Treatment Integrity}

A copy of all nudge messages and delivery receipts was audited and retrieved from the witness notification email address before being entered onto the spreadsheet. One week thereafter each trial, the WMS was interrogated to identify for the following: witness attendance, trial outcome (as long as at least one guilty verdict was identified, the outcome was recorded as guilty), re-scheduling of trial date due to adjournment and quality assurance (the initial data collected on the Excel spreadsheet was re-checked for errors against the WMS).

The Cambridge Crime Harm Index (CHI) was used to numerically score the crime types, in order to consider if non-attendance is potentially linked to levels of harm. To link the CHI scoring to the trial, the grammatical definition from each offence was copied out of the WMS and placed on the spreadsheet against the witness name.

\section{Findings}

\section{Participants}

Random assignment had created two intent-to-treat groups (treatment group $=405$ and control = 406 participants; Figs. 1 and 2), which were well balanced on age, gender, ethnicity, geographic location and victim/witness ratio (Fig. 3) (Cumberbatch 2017).

All people warned to give evidence at the magistrates' court for a trial were clearly marked ' $\mathrm{V}$ ' for victim and ' $\mathrm{W}$ ' for witness. The data identified the required ratio of victims to witnesses was almost a perfect $1: 1$. However the random assignment realised a slightly disproportionate ratio of victims and witness for the control and treatment groups, as illustrated in Fig. 4.

\section{Treatment Integrity with Text Messages}

Figure 5 displays the percentage of those witnesses in the treatment group who actually were sent a reminder message within 3 days before their appearance date.

The $16 \%$ represents 66 members of the treatment group where the reminder text messages were not sent. Of the $16 \%, 26$ witnesses were formally de-warned at the request of the CPS due to them no longer being required at the trial, trial adjournment for re-scheduling or trial withdrawal. A further two witnesses informed the police at the last moment with their refusal to attend the court. This left 38 messages that were not sent out of the 405 in the treatment group, which was due to oversight or caseworkers 


\section{Control Ethnicity Split}

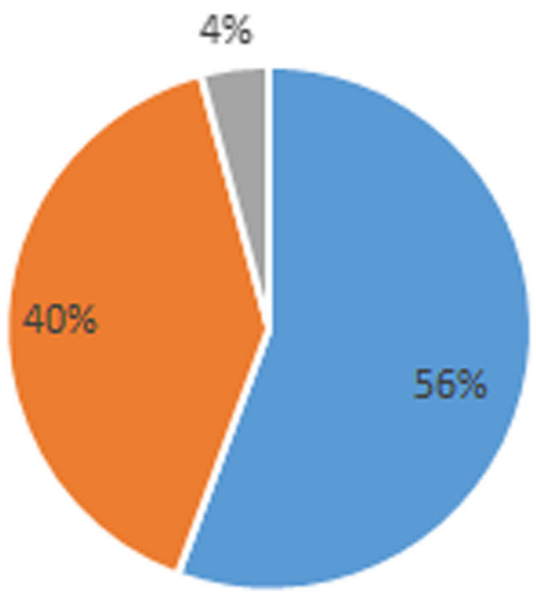

\section{- British ㅁ Not Stated ㅁ Other}

Fig. 1 Percentage of control ethnicity split

being away from work due to leave or sickness and the work not being re-allocated. The clear instruction on who should receive a text message can be seen within an example of a weekly circular in appendix 3 .

The $84 \%$ treatment integrity was checked by an audit of the success to determine if the messages had been delivered. Figure 6 illustrates the successful delivery rate of the text messaging.

The $16 \%$ labelled as not applicable (N/A) illustrates the treatment group participants who had no text message (as per Fig. 5). From the remaining $84 \%$, only $2 \%$ (nine) of notifications from witness mobile phone numbers received a failure message, and the remaining 330 messages were successfully delivered via Microsoft Outlook. This displayed a $97.35 \%$ accuracy rate in the entry of mobile phone numbers on the WMS. Furthermore, no one from the control group was sent a text message. This result was due to the failsafe method of not disclosing any personal details relating to the control group amongst the caseworkers.

\section{Does a Text Message Reminder Reduce Non-attendance?}

When looking at the intention-to-treat design, there was a difference in magistrates' court appearance of the victims and witnesses randomly assigned to the treatment and control groups; in other words, what is the outcome of text message reminders versus normal pre-trial warnings? The RCT findings are clearly illustrated in Fig. 7. 


\section{Treatment Ethnicity Split}

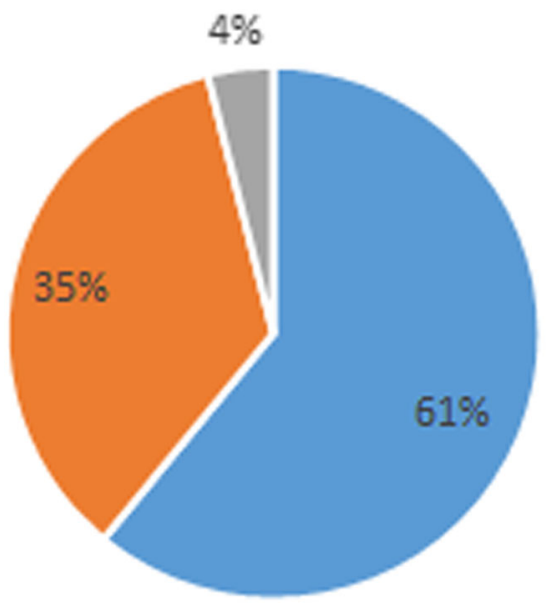

\section{aritish ㅁ Not Stated $\|$ Other}

Fig. 2 Percentage of treatment ethnicity split

Both RCT groups were of equal size (control $=406$, treatment $=405)$. The attendance rate was $77.83 \%$ (316) within the control group, with a $2 \%$ reduced attendance rate of $75.56 \%$ (306) being recorded in the treatment group. When using an independent t-test, the $p$ value results in 0.444 , demonstrating no significant difference between the two groups. Given the relative success in delivering the treatment group messages, this finding suggests that there is little relationship between text message reminders and attendance rates.

\section{Victim and Witness Ratio}

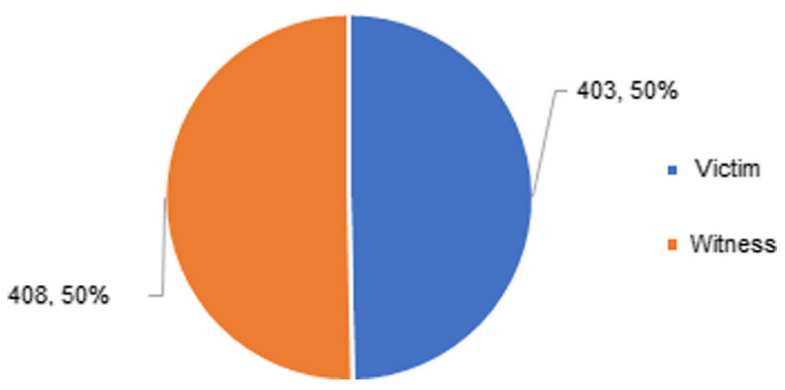

Fig. 3 Victim and witness ratio 
Witness/Victim Ratio Split

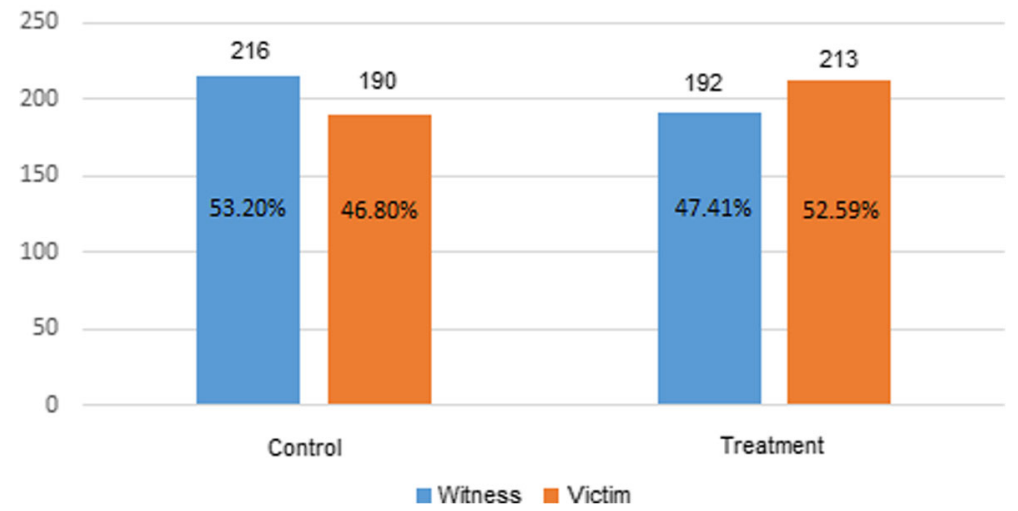

Fig. 4 Witness/victim ratio split

\section{Was Attendance Moderated by Crime Type and Harm Index?}

The four most common crime types were violent, property, traffic and sexual offences. With regard to the listed offences per trial, there were between 1 and 12 offences listed within a court trial at any one time. A more detailed look at the treatment versus control differences in witness appearance rates across crime classifications by categories of offences including violent crimes and property crimes was needed. The numbers from the traffic (91) and sexual (27) offences were too small to allow any meaningful comparative analysis. No differences were found across categories.

As previously suggested, magistrates' courts hear mostly low-level offences which carry low scorings when categorised within the Cambridge Crime Harm Index. For example, the scoring for common offences can be seen with assault by beating which scores 1 , criminal damage to property valued under $£ 5000$ which scores 2 , use threatening/abusive/insulting words/behaviour with intent to cause fear of/provoke unlawful violence which scores 5 and driver of a vehicle fail to stop after road accident/give name and address of self and owner/vehicle details which scores 2 . In addition, some crimes rarely heard at magistrates' court resulted in relatively high

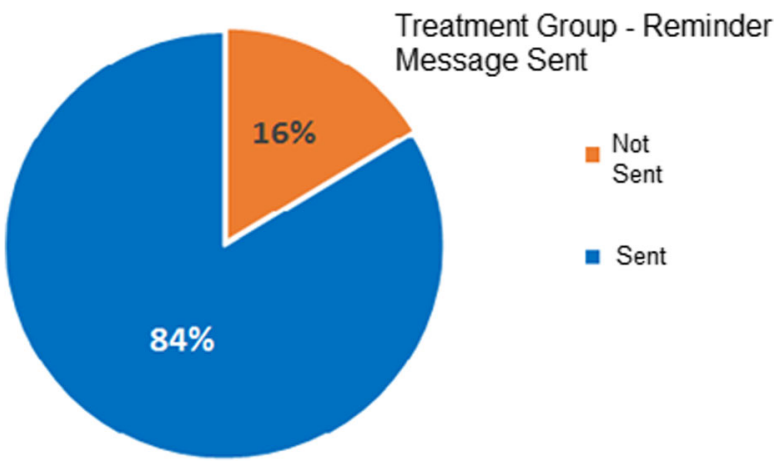

Fig. 5 Percentage of reminder messages sent to the treatment group 


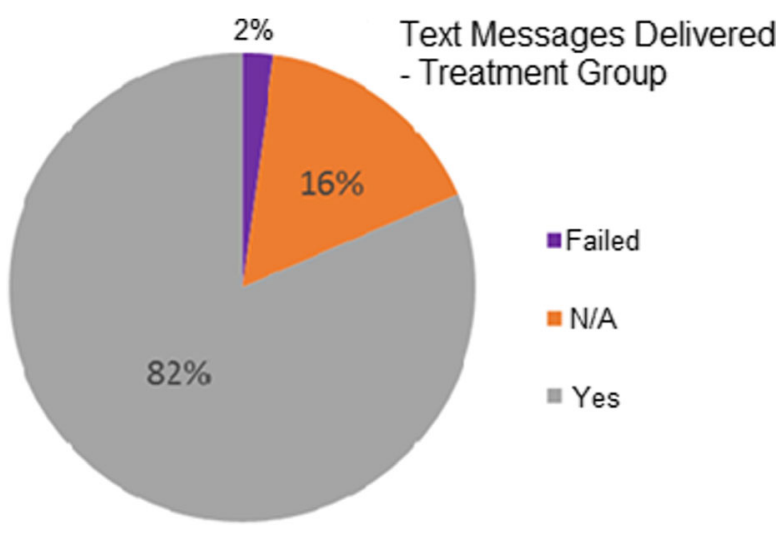

Fig. 6 Percentage of text messages delivered to the treatment group

scorings, for example disclose private sexual photographs and films with intent to cause distress which scores 186 , violent disorder which scores 182.5 and threaten a person with a blade/sharply pointed article in a public place which scores 182.5 .

The analysis found that $378(93.1 \%)$ of the control group and $379(93.5 \%)$ of the treatment group scored below 100 on the CHI. Twenty-four (5.9\%) of the control group and $13(3.2 \%)$ of the treatment group scored between 100 and 200, leaving a small group which scored between 200 and 800 . Each score represents the accumulative scores of all offences within the trial that the witness or victim was scheduled to attend. Further examples of the low-level scores can be seen in the following.

\section{Trial Outcomes}

When tracking the trial outcome, there was a requirement to understand the difference between the treatment and control groups. The categories of results were split into four, these being guilty, not guilty, adjourned and withdrawn. The treatment and control group outcomes are illustrated within the bar chart in Fig. 8.

Fully $58 \%$ of all trials recorded a guilty outcome within the treatment group, compared to $51.2 \%$ within the control group, with a relative difference of $14 \%$ for

\section{Witness Attending}

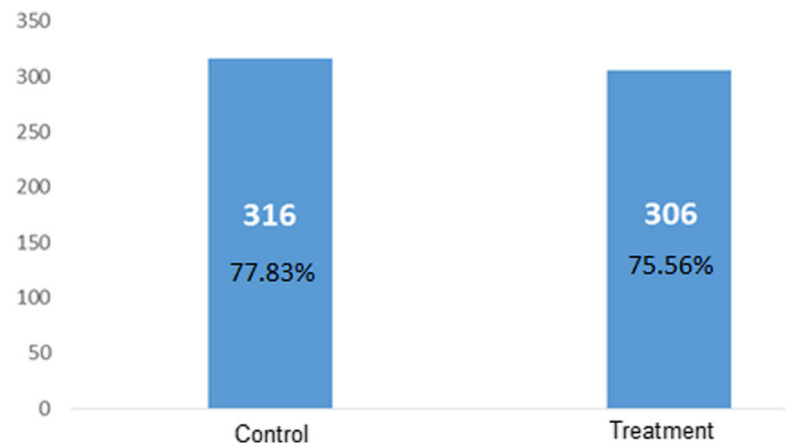

Fig. 7 Percentage of witnesses assigned to the treatment and control groups 
Trial Outcomes

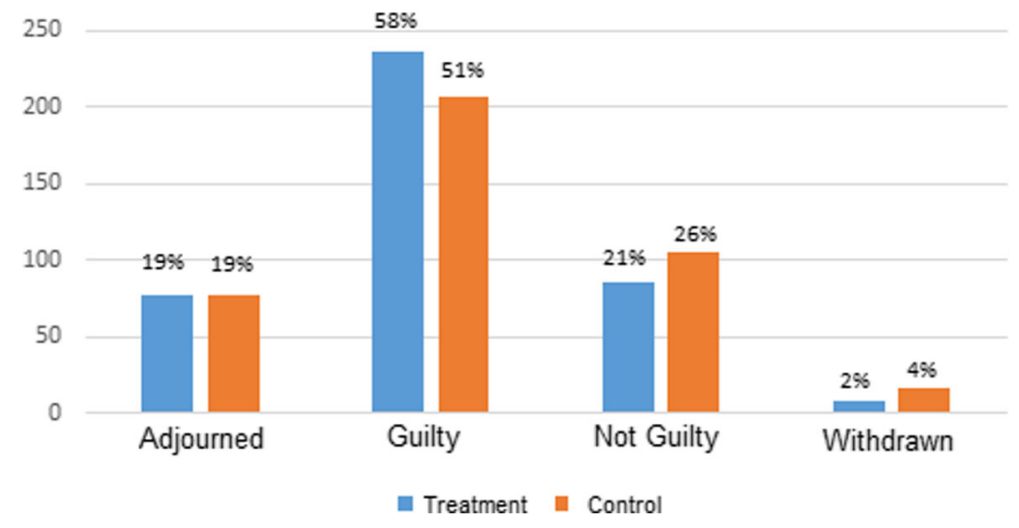

Fig. 8 Percentage of trial outcomes

more guilty verdicts in the treatment group $(p$ value $=0.052)$, a borderline significant result.

\section{Conclusion}

When considering the success and value of this RCT, there are many elements to contemplate. Furthermore, when judging the potential value of this research, there needs to be reflection on what can be next, and how it can be delivered and within what timescales.

\section{Witness Attendance}

The RCT is primarily focused on a very simple question: will text messages to mobile phones of witnesses within 3 days before they are scheduled to appear in court reduce the non-appearance rates for witnesses generally? The answer from this RCT is no. The findings clearly show that the attendance rate was $78 \%$ (316) within the control group, with a $2 \%$ reduced attendance rate of $76 \%$ (306) being recorded in the treatment group. The RCT's required sample size was a minimum of 788, which was surpassed by 811 . The use of an independent t-test identified the $p$ value result as 0.444 , demonstrating no significant relationship between text message reminders and attendance rates. As a result, this research indicates that if a person who is warned to give court evidence does not want to attend, a simple personalised descriptive text message a few days prior to the trial will not change their decision.

\section{Trial Outcomes}

Despite the failure of nudge texts to increase witness attendance, the findings clearly suggest they had some effect on the likelihood of a guilty result recorded. No matter how many offences that the defendant was being charged with, if even one of them was recorded a guilty result on the WMS, it was recorded within the data collection as 
guilty. Thus, there appears to be a clear difference between the treatment and control groups in relation to trials recorded as guilty.

The fact that this result has been recorded for a group of people who have received a short and simple personalised text message is difficult to comprehend. It would be reasonable to label the finding as a 'fluke'; however, consideration needs to be given regarding the overall information system offered to the person giving evidence. Dale et al. (1995) suggest that the linkage between information technology and individual performance is a concern in research which incorporates information systems. There clearly is an information system used for court attendance, and the treatment group has been exposed to the issue of personalised information via technology, as oppose to letter or conversation. Petter et al. (2008) articulate that the impacts of information technology are often indirect and influenced by humans and organisational and environmental factors; therefore, the measurement of an information systems' success is both complex and elusive.

What seems plausible is that without increasing attendance, the nudge texts may have affected the ways in which those who did attend testified in court. That, in turn, could have affected the odds of a guilty verdict. Whether such an effect led to more justice or more wrongful convictions, we cannot say.

\section{Cost-effectiveness}

The RCT found that the present operating procedure required standard letter writing. This entails uploading templates from the WMS into Microsoft Word, editing them, printing and posting at a franking cost of 38p (second class). When considering that initial correspondence that triggers the witness warning to inform the person over the date of the trial, it takes 18 days on average for the person to show their intent. Upon the witness acknowledgement, this process then left the police 40 days to deliver a service to support and assist the person attending court.

When reviewing the $97.35 \%$ successful text delivery rate, it is reasonable to suggest that the replacement of second class written correspondence with text messaging would be quicker, cheaper and more effective. However, there are some hurdles to overcome when considering a complete change or overhaul of working procedures that are integral to the judicial process. In essence, a completely new information system can be built integrating an IT approach alongside the WMS. It is easy to comprehend information notices via text supported by links to interactive Web pages that hold all aspects relating to the court process. Furthermore, online questionnaires for witnesses and victims could inform the police over supporting the need of witnesses. The provision of virtual reality tours of courts, of online victim personal statements, and the serving of witness summons via email could all be added.

In a process that is shared by numerous public sector partners who are all faced with austerity, these transformational ideas need serious consideration. In reality, the text message can be far more than a nudge that made no difference. It can form a new starting point for a quicker and less expensive information system within justice services for witnesses and victims. 


\section{Conclusion}

In assessing the impact of nudge text reminder to reduce non-attendance, the RCT delivered its primary goal. It has been an initiative debated by the police and CPS for some time, and these findings have given an insight with regard to the implementation and effect it carries with trial at magistrates' court. The inability to have a positive impact on court attendance should not be seen as a failure in this instance. Instead, the findings can be used to direct the potential for procedural and policy change when considering how victims and witnesses need to be encouraged and supported when they have a requirement to give evidence at trial. However, with the public funding of the justice system looking even more stretched, change can only come with agreement, joint working and shared cost by all partner agencies concerned.

The RCT spanned a time period which was seeing some considerable flux due to austerity-driven structural change. As a result, when considering the findings, it is clear that the RCT does realise some limitation such as the exclusion of Crown Court trials and high harm offending and not tracking the delivery of postal warnings. However, the RCT was sufficiently powered and delivered a clear picture that treating victims and witnesses with a nudge message for trial does not have any impact on attendance. The RCT did identify sufficient participants to identify statistical significance with even small effect sizes. It used participation that was representative of the population required to give evidence in Staffordshire's courts. Furthermore, it collected data to constructively assess and debate the way in which the police communicate with people required to give evidence.

It is clear that crime type did not appear to impact on attendance in both groups; however, it would have been interesting to have a balance and broad array of offences as oppose to looking at the majority with low-level violence and property cases. The achievement of this can only be done in the future by running an RCT over a longer time period and opening the process up to the Crown Court. This shift in focus will also have the ability to bridge the gap in crime harm, with severity of harm being delivered via the Crown Court. However, there is a greater need to consider how this is delivered to victims and witness that are seen as vulnerable. These people are usually managed in a more considered and delicate manner, as they may be under physical or emotional threat, or potentially be suffering with mental ill-health issues. In essence, the new structural change that Staffordshire Police have can facilitate this with their Vulnerable Victims Unit. Prompting the question: can Web-based 'self-service' victims and witnesses be processed in the masses (quickly and efficiently), while vulnerable victims and witnesses have their own personalised service from a specialist unit?

O'Connor (2011) suggested that the police service wants better big ideas about achieving affordable policing, and to succeed with court attendance, the current practices need to change dramatically. The delivery of this RCT using formal and structured text message notifications contradicts long-term cultural behaviour. The findings clearly indicate that the $97.35 \%$ of text messages were delivered successfully, prompting the question of why are we writing to people at a higher cost in time, resources and material. At a time when the police and partner agencies nationally continue to be in flux over change, while identifying the need to deliver a smarter and more efficient service, this clearly points towards fundamental change. The thought that hard copy letter writing can be replaced by automatically built text messages and 
supported by an interactive Web page must bring some hope for caseworkers. However, changes must be pushed further with the contemplation of a broader Web-based self-service for people attending court. The ability to submit victim personal statements and requests for special measures online, accompanied by Web-based virtual reality induction tours of court to reduce the one-to-one visits facilitated by witness services. There is a reality that more people want a self-service facility, and this idea should not be ignored by the judicial system. To accomplish this, Peffers et al. (2014) suggest a six-step approach: problem identification and motivation, definition of the objectives for a solution, design and development, demonstration, evaluation and communication. This clearly outlines the need for some structured planning and delivery. The CPS estimate that Staffordshire police deliver a service for over 20,000 victims and witnesses of crime in a 12-month period. As a result, there is clear indication that new ways of working will deliver a better and more affordable way of work.

If the findings from this RCT are going to be used for delivering change, some clear and realistic implementation is required in a time that is demanding quicker and smarter initiatives. Fixen et al. (2005) set out an implementation framework for evidence-based interventions. They outline five key components that need to interact: the new practice, the practitioner delivering the practice, appropriate communication to train and educate the practitioner, feedback following evaluation and influencing factors such as funding and partners or victims and witnesses in this case. A framework is essential to a management structure that wishes to track and then translate the findings into a new police initiative. Even though there is a desire for quick success, the decision-making within a multi-faceted framework of implementation must remain devoid of delusional optimism over success (Kahneman 2012) and instead focus on rational weighting of gains, losses and probabilities.

The delivery of such a task must be executed by transformational leaders with drive and focus to educate, intervene and engage the work force. As police numbers reduce and harm crime remains, the interrogation and change of working practices through targeting, testing and tracking will accelerate the use and success of evidence-based policing. It is clear that the purpose of the task must remain larger than the leader (Sherman et al. 2014). Furthermore, with the radical change in police structure over recent years via the elected office of the 'Police and Crime Commissioner', Sherman (2013) suggests the position can be used to oversee new police processes for independent governance. This can ensure the focus and measurement of new suggestions such as this one will remain focused upon public safety. Skogan (2008) postulates that the inability to measure new practices can bring failure upon change.

The ponderous issue of the treatment group realising (nearly) significantly higher guilty finding than the control can stimulate debate. It is important to articulate that there is no convincing rational to indicate that this finding was a fluke or the nudge text reminder influenced evidence presented with the court. When exploring research relating to nudge text messages, the focus has been in relation to appointments and the collection of money. There is no nudge text in the RCTs of real consequence which relates to the judicial process. This is disappointing when evidence can clearly be cultivated to impact on potential cost savings and effectiveness. As a result, further research is required to assist the way in which the police engage and support individuals that are crucial to the justice system. Ways of work that have historically been effective for the 
police need review and transformation. However, in this case, procedural and policy change must be directed and driven by an evidence-based approach.

Acknowledgements The authors wish to thank the Staffordshire Police Witness Care Supervisor Linda Thomas for her support and guidance of the delivery of this RCT.

Open Access This article is distributed under the terms of the Creative Commons Attribution 4.0 International License (http://creativecommons.org/licenses/by/4.0/), which permits unrestricted use, distribution, and reproduction in any medium, provided you give appropriate credit to the original author(s) and the source, provide a link to the Creative Commons license, and indicate if changes were made.

\section{References}

Bargh, J. A. (1982). Attention and automaticity in the processing of self-relevant information. J Pers Soc Psychol, 43, 425-436.

BBC (2016). Thousands of trials end over no-show witnesses - watchdog, https://www.bbc.co.uk/news/uk35347781. 14/07/2017.

Conway, A. R. A., \& Cowan, N. (2001). The cocktail party phenomenon revisited: the importance of working memory capacity. Psychon Bull Rev, 8(2), 331-335.

Cumberbatch, J. R. (2017) Increasing Witness Appearance with Text Message Reminders of Magistrate Court Dates: A Randomised Controlled Trial. Unpublished in MSt thesis, University of Cambridge.

Dale, L., Goodhue, D. L., \& Thompson, R. L. (1995). Task-technology fit and individual performance. MIS Q, 19(2), 213-236.

Davis, R. C. (1983). Victim/witness non-cooperation: a second look at a persistent phenomenon. J Crim Just, 11(4), 287-299.

Erez, E., \& BienKowska, E. (1993). Victim participation in proceedings and satisfaction with justice in the continental system: the case of Poland. J Crim Just, 21, 41-60.

Fixen, D. L., Naoom, S. F., Blase, K. A., Friedman, R. M. \& Wallace, F. (2005). Implementation Research: Tampa, FL. University of South Florida, Louis de la Parte Florida Mental Health Institute, The National Implementation Network A Synthesis of the Literature.

Halpern, D. (2015). Inside the nudge unit. London: WH Allen.

Haynes, L.C, Green, D.P., Gallagher, R., John P., and Torgerson, D.J. (2013) Collection of delinquent fines: an adaptive randomized trial to assess the effectiveness of alternative text messages. Journal of Policy Analysis and Management, 718-730.

Her Majesty's Inspectorate of Constabulary (HMIC) and Her Majesty's Crown Prosecution Service Inspectorate (HMCPSI). (2013). Getting cases ready for court - a joint review of the quality of prosecution case files by HMIC and HMCPSI, https://www.justiceinspectorates.gov.uk/hmic/media/gettingcases-ready-for-court.pdf, 28/04/2017, 0928hrs.

House of Commons Committee of Public Accounts. (2017) Efficiency in the criminal justice system-first report of session 2016-17, https:/www.publications.parliament.uk/pa/cm201617/cmselect/cmpubacc/72 172.pdf, 28/04/2017, 0947hrs.

Kahneman, D. (2012). Thinking, fast and slow. London: Penguin.

Klein, G. (2007). Performing a project pre-mortem. Harv Bus Rev, 85(9).

Ministry of Justices. (2015). Code of practice for victims of crime https://www.gov. uk/government/uploads/system/uploads/attachment_data/file/476900/code-of-practice-for-victims-ofcrime.PDF, 27/04/2017 10:58hrs.

Ministry of Justice (2015) Criminal court statistics quarterly, England and Wales. https://www.gov. uk/government/uploads/system/uploads/attachment_data/file/437672/ccsq-bulletin-january-march-2015. pdf, 15/11/2017 10:13hrs.

National Audit Office, Ministry of Justice. (2016). Efficiency in the criminal justice system. https://www.nao. org.uk/wp-content/uploads/2016/03/Efficiency-in-the-criminal-justice-system.pdf. 1924hrs 22/05/2017.

O’Connor, D. (2011) Conference on evidence based policing keynote speech, Lady Mitchell Hall "Adapting the blues", 4th July 2011. 
Peffers, K., Rothenburg, R., Tuunanen, T. A., Chatterjee, S., \& Pages, A. (2014). Design science research methodology for information systems research. J Manag Inf Syst, 45-77.

Petter, S., DeLone, W., \& McLean, E. (2008). Measuring information systems success: models, dimensions, measures, and interrelationships. Eur J Inf Syst, 17(3), 236-263.

Shapiro, K., Caldwell, J., \& Sorensen, R. (1997). Personal names and the attentional blink: a visual "cocktail party" effect. J Exp Psychol Hum Percept Perform, 23, 504-514.

Sherman, L. W. (2013). 'The rise of evidence-based policing: targeting, testing and tracking', crime and justice in America, 1975-2025. Crime and Justice, 42, 377-452.

Sherman, L.W., Williams, S., Ariel, B., Strang, L.R., Wain, N., Slothower, M. \& Norton, A. (2014) An integrated theory of hot spot patrol strategy: implementing prevention by scaling up and feeding back. Journal of Contemporary Criminal Justice, p1-28.

Skogan, W. G. (2008). Why reforms fail. Policing \& Society, 18(1), 23-34.

Jonathan R. Cumberbatch GCE, PGDip, BSc(Hons), MSc, MSt, Cantab, is the Firearms and Explosives Licensing Manager for Staffordshire and West Midlands Police.

Geoffrey C. Barnes Ph.D., is a Senior Lecturer in Applied Criminology at the University of Cambridge, Institute of Criminology. 